Published in final edited form as:

J Orthop Trauma. 2012 June ; 26(6): 370-378. doi:10.1097/BOT.0b013e31822421e2.

\title{
Development and Validation of an Instrument to Predict Functional Recovery in Tibial Fracture Patients: The Somatic Pre-Occupation and Coping (SPOC) Questionnaire
}

\author{
Jason W. Busse, DC, PhD, \\ Institute for Work \& Health, 481 University Avenue, Suite \#800, Toronto, Ontario, Canada, M5G \\ 2E9 \\ Mohit Bhandari, MD, MSc, \\ McMaster University 293 Wellington Street North, Suite 110 Phone (905) 527-4322 ext. 44648 \\ Fax (905) 523-6776 bhandam@mcmaster.ca \\ Gordon H. Guyatt, MD, MSc, \\ McMaster University 1200 Main Street West, Rm. 2C12 Hamilton, Ontario, Canada L8N $3 Z 5$ \\ Phone (905) 525.9140 x 22160 Fax (905)524.3841 guyatt@mcmaster.ca \\ Diane Heels-Ansdell, MSc, \\ McMaster University 1200 Main Street West, HSC-2C13 Hamilton, Ontario L8S $3 Z 5$ Phone (905) \\ 525.9140, ext. 22944 ansdell@mcmaster.ca \\ Abhaya V. Kulkarni, MD, PhD, \\ Hospital for Sick Children, Room 1503555 University Avenue Toronto, Ontario, Canada M5G \\ 1X8 Phone (416) 813-6427 Fax (416) 813-4975 abhaya.kulkarni@sickkids.ca
}

Scott Mandel, MD,

McMaster University Department of Surgery M8-414 Victoria Ave north Hamilton, ON L8L 5G8

Phone (905) 526-1880 Fax (905) 526-6309

David Sanders, MD,

London Health Sciences Centre - Victoria Hospital E4-123, 800 Commissioners Road East

London, Ontario N6A 5W9

Emil Schemitsch, MD,

St. Michaels' Hospital 55 Queen St. E., \#800 Toronto, ON M5C 1R6

Marc Swiontkowski, MD,

University of Minnesota Department of Orthopaedic Surgery 2512 South 7th Street Suite R200 Minneapolis, MN 55454 Phone (612) 273-8000 Fax (612) 273-7959 swion001@umn.edu

Paul Tornetta III, MD,

Boston Medical Center 850 Harrison Avenue, Dowling 2 North Boston, MA 02118

Eugene Wai, MD, and

Ottawa Hospital Civic Campus Orthopedic Surgery C 2 Room 21781053 Carling Avenue Ottawa, Ontario K1Y 4E9 Phone: (613) 798-5555 Ext. 19138 Fax: (613) 761-4944

Stephen D. Walter, PhD

Faculty of Health Sciences McMaster University Health Sciences Centre, Room 2C16 1200 Main Street West Hamilton, ON L8N $3 Z 5$ Phone (905) 525.9140 x 23387 Fax (905) 577.0017 walter@mcmaster.ca

\section{Abstract}




\section{Competing interests: None declared.}

The SPRINT investigators and the Medically Unexplained Syndromes Study Group

The writing group [Jason W. Busse (chair), Mohit Bhandari, Gordon H. Guyatt, Diane Heels-Ansdell, Abhaya V. Kulkarni, Scott

BusSeetdal, David Sanders, Emil Schemitsch, Marc Swiontkowski, Paul Tornetta III, Eugene Wai, and Stephen D. Walter] assumespage 2 responsibility for the overall content and integrity of the manuscript. Drs Bhandari and Guyatt, as Principal Investigators, had full access to the study data and take responsibility for its integrity. The following persons participated in the SPRINT Study: Study Trial Co-Principal Tnvestigators: Mohit Bhandari; Gordon Guyatt; Steering Committee: Chair: Gordon Guyatt; Mohit Bhandari; David W. Sanders; Emil H. Schemitsch; Marc Swiontkowski; Paul Tornetta III; Stephen Walter; Central Adjudication Committee: Chair: Gordon Guyatt; Mohit Bhandari; David W. Sanders; Emil H. Schemitsch; Marc Swiontkowski.; Paul Tornetta III; Stephen Walter; Steering / Adjudication / Writing Committee: Chair: Gordon Guyatt; Mohit Bhandari; David W. Sanders; Emil H. Schemitsch; Marc Swiontkowski; Paul Tornetta III; Stephen Walter; SPRINT Methods Centre Staff: McMaster University, Hamilton, Ontario: Sheila Sprague; Diane Heels-Ansdell; Lisa Buckingham; Pamela Leece; Helena Viveiros; Tashay Mignott; Natalie Ansell; Natalie Sidorkewicz; University of Minnesota, Minneapolis, Minnesota: Julie Agel; Data Safety and Monitoring Board (DSMB): Chair: Claire Bombardier; Jesse A. Berlin; Michael Bosse; Bruce Browner; Brenda Gillespie; Alan Jones; Peter O’Brien; Site Audit Committee: Julie Agel; Sheila Sprague; Rudolf Poolman; Mohit Bhandari.

Investigators: London Health Sciences Centre / University of Western Ontario, London, Ontario: David W. Sanders; Mark D. Macleod; Timothy Carey; Kellie Leitch; Stuart Bailey; Kevin Gurr; Ken Konito; Charlene Bartha; Isolina Low; Leila V. MacBean; Mala Ramu; Susan Reiber; Ruth Strapp; Christina Tieszer; Sunnybrook Health Sciences Centre / University of Toronto, Toronto, Ontario: Hans J. Kreder; David J. G. Stephen; Terry S. Axelrod; Albert J.M. Yee; Robin R. Richards; Joel Finkelstein; Wade Gofton; John Murnaghan; Joseph Schatztker; Michael Ford; Beverly Bulmer; Lisa Conlan; Hospital du Sacre Coeur de Montreal, Montreal, Quebec: G.Yves Laflamme; Gregory Berry; Pierre Beaumont; Pierre Ranger; Georges-Henri Laflamme; Sylvain Gagnon; Michel Malo; Julio Fernandes; Marie-France Poirier; St. Michael's Hospital / University of Toronto, Toronto, Ontario: Emil H. Schemitsch; Michael D. McKee; James P. Waddell; Earl R. Bogoch; Timothy R. Daniels; Robert R. McBroom; Milena R. Vicente; Wendy Storey; Lisa M. Wild; Royal Columbian Hospital / University of British Columbia, New Westminster/Vancouver, British Columbia: Robert McCormack; Bertrand Perey; Thomas J. Goetz; Graham Pate; Murray J. Penner; Kostas Panagiotopoulos; Shafique Pirani; Ian G. Dommisse; Richard L. Loomer; Trevor Stone; Karyn Moon; Mauri Zomar; Wake Forest Medical Center / Wake Forest University Health Sciences, Winston-Salem, North Carolina: Lawrence X. Webb; Robert D. Teasdall; John Peter Birkedal; David Franklin Martin; David S. Ruch; Douglas J. Kilgus; David C. Pollock; Mitchel Brion Harris; Ethan Ron Wiesler; William G. Ward; Jeffrey Scott Shilt; Andrew L. Koman; Gary G. Poehling; Brenda Kulp; Boston Medical Center / Boston University School of Medicine, Boston, Massachusetts: Paul Tornetta III; William R. Creevy; Andrew B. Stein; Christopher T. Bono; Thomas A. Einhorn; T. Desmond Brown; Donna Pacicca; John B. Sledge III; Timothy E. Foster; Ilva Voloshin; Jill Bolton; Hope Carlisle; Lisa Shaughnessy; Wake Medical Center, Raleigh, North Carolina: William T. Obremskey; C. Michael LeCroy; Eric G. Meinberg; Terry M. Messer; William L. Craig III; Douglas R. Dirschl; Robert Caudle; Tim Harris; Kurt Elhert; William Hage; Robert Jones; Luis Piedrahita; Paul O. Schricker; Robin Driver; Jean Godwin; Vanderbilt University Medical Center, Nashville, Tennessee: William T. Obremskey; Philip James Kregor; Gregory Tennent; Lisa M. Truchan; Marcus Sciadini; Franklin D. Shuler; Robin E. Driver; Mary Alice Nading; Jacky Neiderstadt; Alexander R. Vap; MetroHealth Medical Center, Cleveland, Ohio:Heather A. Vallier; Brendan M. Patterson; John H. Wilber; Roger G. Wilber; John K. Sontich; Timothy Alan Moore; Drew Brady; Daniel R. Cooperman; John A. Davis; Beth Ann Cureton; Hamilton Health Sciences, Hamilton, Ontario: Scott Mandel; R. Douglas Orr; John T.S. Sadler; Tousief Hussain; Krishan Rajaratnam; Bradley Petrisor; Mohit Bhandari; Brian Drew; Drew A. Bednar; Desmond C.H. Kwok; Shirley Pettit; Jill Hancock; Natalie Sidorkewicz; Regions Hospital, St. Paul, Minnesota: Peter A. Cole; Joel J. Smith; Gregory A. Brown; Thomas A. Lange; John G. Stark; Bruce A. Levy; Marc F. Swiontkowski; Mary J. Garaghty; Joshua G. Salzman; Carol A. Schutte; Linda Tastad; Sandy Vang; University of Louisville School of Medicine, Louisville, Kentucky: David Seligson; Craig S. Roberts; Arthur L. Malkani; Laura Sanders; Carmen Dyer; Jessica Heinsen; Langan Smith; Sudhakar Madanagopal; Linda Frantz-Bush; Memorial Hermann Hospital, Houston, Texas: Kevin J. Coupe; Jeffrey J. Tucker; Allen R. Criswell; Rosemary Buckle; Alan Jeffrey Rechter; Dhiren Shaskikant Sheth; Brad Urquart; Thea Trotscher; Erie County Medical Center / University of Buffalo, Buffalo, New York: Mark J. Anders; Joseph M. Kowalski; Marc S. Fineberg; Lawrence B. Bone; Matthew J. Phillips; Bernard Rohrbacher; Philip Stegemann; William M. Mihalko; Cathy Buyea; University of Florida - Jacksonville, Jacksonville, Florida: Stephen J. Augustine; William Thomas Jackson; Gregory Solis; Sunday U. Ero; Daniel N. Segina; Hudson B. Berrey; Samuel G. Agnew; Michael Fitzpatrick; Lakina C. Campbell; Lynn Derting; June McAdams; Academic Medical Center, Academic Medical Center, Amsterdam, The Netherlands: J. Carel Goslings; Kees Jan Ponsen; Jan Luitse; Peter Kloen; Pieter Joosse; Jasper Winkelhagen; Raphaël Duivenvoorden; University of Oklahoma Health Science Center, Oklahoma City, Oklahoma: David C. Teague; Joseph Davey; J. Andy Sullivan; William J. J. Ertl; Timothy A. Puckett; Charles B. Pasque; John F. Tompkins II; Curtis R. Gruel; Paul Kammerlocher; Thomas P. Lehman; William R. Puffinbarger; Kathy L. Carl; University of Alberta / University of Alberta Hospital / Royal Alexandra Hospital, Edmonton, Alberta: Donald W. Weber; Nadr M. Jomha; Gordon R. Goplen; Edward Masson; Lauren A. Beaupre; Karen E. Greaves; Lori N. Schaump; Greenville Hospital System, Greenville, South Carolina: Kyle J. Jeray; David R. Goetz; David E. Westberry; J. Scott Broderick; Bryan S. Moon; Stephanie L. Tanner; Foothills General Hospital, Calgary, Alberta: James N. Powell; Richard E. Buckley; Leslie Elves; Saint John Regional Hospital, Saint John, New Brunswick: Stephen Connolly; Edward P. Abraham; Trudy Steele; Oregon Health \& Sciences University, Portland, Oregon: Thomas Ellis; Alex Herzberg; George A. Brown; Dennis E. Crawford; Robert Hart; James Hayden; Robert M. Orfaly; Theodore Vigland; Maharani Vivekaraj; Gina L. Bundy; University of California, San Francisco, San Francisco General Hospital, San Francisco, California: Theodore Miclau III; Amir Matityahu; R. Richard Coughlin; Utku Kandemir; R. Trigg McClellan; Cindy Hsin-Hua Lin; Detroit Receiving Hospital, Detroit, Michigan: David Karges; Kathryn Cramer; J. Tracy Watson; Berton Moed; Barbara Scott; Deaconess Hospital Regional Trauma Center and Orthopaedic Associates, Evansville, Indiana: Dennis J. Beck; Carolyn Orth; Thunder Bay Regional Health Science Centre, Thunder Bay, Ontario: David Puskas; Russell Clark; Jennifer Jones; Jamaica Hospital, Jamaica, New York: Kenneth A. Egol; Nader Paksima; Monet France; Ottawa Hospital - Civic Campus, Ottawa, Ontario: Eugene K. Wai; Garth Johnson; Ross Wilkinson; Adam T. Gruszczynski; Liisa Vexler.

This is a PDF file of an unedited manuscript that has been accepted for publication. As a service to our customers we are providing this early version of the manuscript. The manuscript will undergo copyediting, typesetting, and review of the resulting proof before it is published in its final citable form. Please note that during the production process errors may be discovered which could affect the content, and all legal disclaimers that apply to the journal pertain. 
physical trauma.

Methods-We developed and validated an instrument designed to capture the impact of patients' beliefs on functional recovery from injury; the Somatic Pre-occupation and Coping (SPOC) questionnaire. At 6-weeks post-surgical fixation, we administered the SPOC questionnaire to 359 consecutive patients with operatively managed tibial shaft fractures. We constructed multivariable regression models to explore the association between SPOC scores and functional outcome at 1year, as measured by return to work and short form-36 (SF-36) physical component summary (PCS) and mental component summary (MCS) scores.

Results-In our adjusted multivariable regression models that included pre-injury SF-36 scores, SPOC scores at 6-weeks post-surgery accounted for $18 \%$ of the variation in SF-36 PCS scores and $18 \%$ of SF-36 MCS scores at 1-year. In both models, 6-week SPOC scores were a far more powerful predictor of functional recovery than age, gender, fracture type, smoking status, or the presence of multi-trauma. Our adjusted analysis found that for each 14 point increment in SPOC score at 6-weeks (14 chosen on the basis of half a standard deviation of the mean SPOC score) the odds of returning to work at 1 -year decreased by $40 \%$ (odds ratio $=0.60 ; 95 \% \mathrm{CI}=0.50$ to 0.73 ).

Conclusion-The SPOC questionnaire is a valid measurement of illness beliefs in tibial fracture patients and is highly predictive of their long-term functional recovery. Future research should explore if these results extend to other trauma populations and if modification of unhelpful illness beliefs is feasible and would result in improved functional outcomes.

\section{INTRODUCTION}

Some authors have suggested that patients' expectations of recovery and illness perceptions may influence their outcome, ${ }^{1,2}$ and a recent systematic review has provided support for this hypothesis. ${ }^{3}$ Specifically, positive patient expectations were found to be associated with better clinical outcomes across a range of conditions. A subsequent prospective study found that injured workers' recovery beliefs, elicited through telephone interview, were independent predictors of clinical outcome. ${ }^{4}$ Other studies have also found patients' belief systems to be independent predictors for recovery from acute low back pain, ${ }^{5}$ prognosis following whiplash-associated disorders, ${ }^{6}$ and the development of treatment-resistant low back pain ${ }^{7}$ and idiopathic chronic pain ${ }^{8}$. In other words, both disease - that component of a patient's presenting complaint that can be objectively defined - and illness - the patient's subjective experience of their complaint - appear to influence recovery. ${ }^{9}$ Currently there are no standard procedures in place that attempt to capture the contribution of illness towards recovery from physical trauma. As a result, clinicians tend to focus on disease markers, and some patients do not to recover to a level commensurate with objective improvements in their disease.

It is possible that the subjective illness experience of patients with healing fractures may influence their recovery. With approximately 6 million fractures annually in North America, ${ }^{10,11}$ it would be of considerable interest to determine if patients' recovery expectations and illness perceptions are independent predictors of functional recovery from fracture. The current investigation is an attempt to construct and determine the initial psychometric properties of a self-administered questionnaire designed to predict the contribution of illness beliefs towards functional outcomes of trauma: the Somatic Preoccupation and Coping (SPOC) questionnaire. Our goal was not to develop a discriminative instrument measuring somatic preoccupation and coping, but rather to develop a predictive instrument that draws on these areas to allow identification of individuals more or less likely to do well after surgery. ${ }^{12}$ 


\section{SCALE DEVELOPMENT}

\section{Literature Search and Content Expert Consultation}

In an effort to locate existing instruments that examined the impact of recovery expectations and illness perceptions on fracture healing, one of us (JWB) conducted a search of MEDLINE. The search strategy was designed to retrieve English-language articles from 1966 to March 2002, with a title or abstract containing the medical subject heading (MeSH) "fracture healing", and at least of one of the MeSH subheadings "self-assessment", "selfconcept" or "attitude to health", or at least one of the following six key words: "expectation", "belief", "prediction", "recover", "outcome" or "improve". In addition, a content expert in the area of illness beliefs was consulted to identify any questionnaires germane to our endeavour.

Our literature search yielded 257 potentially relevant articles. Most articles addressed related areas, such as measurement of quality of life, only indirectly related to recovery expectations. We identified seven articles which, on the basis of their titles and abstracts, showed potential for measuring recovery expectations. ${ }^{13-19}$ Detailed review of these articles revealed that they too did not examine patients' recovery expectations. They did, however, provide information on additional potential predictors of clinical outcome following fracture that we incorporated into our regression models. Communication with a content expert (a psychiatrist with advanced research training relevant to our area of study) led to the acquisition of four existing instruments designed to explore or investigate or measure patients' illness beliefs: the General Health Questionnaire, ${ }^{20}$ the Somatization Subscale of the Symptom Check List-90, ${ }^{21}$ the Chalder Fatigue Questionnaire, ${ }^{22}$ and the Illness Attitude Scales ${ }^{23}$. None of these, in our judgment, comprehensively measured all of potential predictors we thought important. We therefore chose selected items from the instruments (with modifications for the target population, e.g. specifying that the clinical focus was patient's injury), and in addition worked with the trauma surgeons on our study team to devise questionnaire items based on their clinical experiences. These items involved common symptom complaints and questions designed to explore patient's belief about their prognosis. The resulting SPOC questionnaire consisted of 60 items, with seven response options ranging from 0 to 6 for each item. Response options were "all of the time", "most of the time", "a good bit of the time", "some of the time", "a little of the time", "hardly any of the time", and "none of the time" for questions that asked about frequency, and "completely agree", "strongly agree", "agree", "uncertain", "disagree", "strongly disagree", and "completely disagree" for questions that queried level of endorsement.

\section{Face and Content Validity}

The resultant instrument was divided into 5 hypothetical domains: symptoms, perceived prognosis, energy level, general health, and additional health concerns. Two orthopaedic trauma surgeons, one with formal training in clinical epidemiology, reviewed the draft instrument and commented on whether the instrument appeared to be assessing the desired qualities (face validity), and whether the instrument was likely to sample all relevant domains (content validity).

\section{Administration}

From July 2000 to September 2005, 1319 patients with open (Gustilo Type I-IIIb) and closed (Tscherne Type 0-3) tibial shaft fractures amenable to operative fixation with an intramedullary nail were enrolled in a multi-centre, randomized controlled trial, the eponym for which is SPRINT ( $\underline{\text { Study to }}$ Prospectively evaluate Reamed Intramedullary Nails in Tibial fractures). ${ }^{24}$ Each institution's ethics review board approved the study, which was registered at Clinicaltrial.gov (Identifier: NCT00038129). Details of the study design have 
been previously described. ${ }^{25}$ Of this population, 359 consecutive patients agreed to complete the SPOC questionnaire at their 6-week post-operative follow-up, 316 of whom provided complete data (Table 1). We excluded questionnaires with incomplete data from our analyses. Factor analysis requires a recommended minimum of 300 survey respondents for 60 items ( 5 respondents per item when the sample size is over 100); ${ }^{26}$ thus we restricted our data collection to a consecutive subgroup of SPRINT patients to reduce unnecessary respondent burden. We collected data on an additional 59 patients to account for loss to follow-up for our dependent variables, short form-36 (SF-36) questionnaire scores and employment status collected at 12 months post surgical fixation. We approached SPRINT investigators and centres with demonstrated recruitment success to facilitate administration of the SPOC questionnaire.

\section{Questionnaire Refinement}

We analyzed all data using the SPSS Advanced Statistics software package (version 17.0, SPSS Inc., Chicago, Illinois, USA). We calculated the means and associated standard deviation (SD) for all items in our questionnaire. Items with a mean score of $<1$ (the range for each item was 0-6) were excluded, as they were assumed to capture no meaningful distress feature. Items showing a SD $<1$ were also excluded, as this limited variation suggested that the item was rated homogenously for the majority of patients, thus adding no substantial information and discriminant power. Following screening for item score means and SD's, 9 items were removed.

Using the remaining items, we constructed a correlation matrix which provided an assessment of the strength of the relation between our variables. The correlation between any two variables can range from -1.0 (perfectly negatively correlated) to 1.0 (perfectly positively correlated). Items that are highly correlated are likely to be measuring the same underlying concept and therefore provide redundant information. We reviewed the matrix to explore the pattern of relationships among items; specifically for pairs of items in which any correlation coefficients were $\searrow$.7. Review of the correlation matrix for the remaining items found 8 pairs of variables with correlation coefficients $\geq 0.7$, and 8 of these 16 items were removed; we eliminated the smallest possible number of variables to eliminate the high correlations. This left 43 items.

To test if our data was suitable for factor analysis we calculated the Kaiser-Meyer-Olkin (KMO) measure of sampling adequacy and Bartlett's test. The KMO statistic varies between 0 and 1. A value of 1 indicates that patterns of correlations are relatively independent and so factor analysis should yield distinct and reliable factors. In general, values between 0.5 and 0.7 are mediocre, between 0.7 and 0.8 are good, between 0.8 and 0.9 are very good, and $>0.9$ are excellent. ${ }^{27}$ Bartlett's measure tests the null hypothesis that the original items have an identity correlation matrix. In order to complete a factor analysis the variables must be related to some degree, whereas in an identity matrix all the off-diagonal entries are zero. A significant Bartlett's measure test ( $\mathrm{p} \unlhd$.05) confirms that the correlation matrix is significantly different from an identity matrix, and therefore that factor analysis is appropriate. The KMO statistic on these items was 0.93 and Bartlett's test was highly significant $(\mathrm{p}<0.001)$; factor analysis was therefore deemed appropriate.

Principal component analysis (a variant of factor analysis) was used to estimate the number of fundamental dimensions, or factors, underlying the observed data, and investigate the loading of individual items on those dimensions. We reviewed both the unrotated factor solution and a varimax rotation. Rotation, if successful, maximizes the loading of each variable on only one of the extracted factors while minimizing the loading on all other factors. We discarded items that failed to result in significant loading on any factor, as defined by an absolute coefficient value of less than 0.4. Principal component analysis 
identified 9 factors that had eigenvalues greater than 1.0, and varimax rotation was shown to optimize the factor structure. Before rotation, factor 1 accounted for $32.7 \%$ of the variation, compared to values ranging from $6.1 \%$ to $2.4 \%$ for the other 8 factors, and after rotation the variation explained by factor 1 was reduced to $12.4 \%$ and the relative importance of the remaining factors was much more evenly distributed. The variation explained by all 9 factors was $62.4 \%$.

A scree plot is a line graph that shows the fraction of total variance in the outcome data that is explained by each factor, and factors are ordered from most to least variance explained. Such a plot can often show a clear separation in the fraction of total variance between the 'most important' components and the 'least important' components. We constructed a scree plot in order to visually explore how many factors to retain. The scree plot suggested the retention of 4 factors compromising 27 -items that accounted for $37.4 \%$ of the variation. Possible scores for the resultant SPOC questionnaire ranged from 0 to 162 , with higher scores representing greater somatic pre-occupation and worse coping. Our final 27-item SPOC questionnaire contained: 6 items modified from the General Health Questionnaire, 4 items modified from the Somatization Subscale of the Symptom Check List-90, 7 items modified from the Chalder Fatigue Questionnaire, no items from the Illness Attitude Scales, and 10 items generated by our group.

Review of the questions loaded onto each factor identified the following themes: (1) somatic complaints -10 items, (2) coping - 6 items, (3) energy -7 items, and (4) optimism - 4 items. Abridged SPOC questionnaire items, and their factor loadings, are presented in Table 2. The mean SPOC score in our population was $57.1(\mathrm{SD}=28.5)$, values ranged from 0 to 147 , and the distribution was approximately normal (median $=53.5$, skewness $=0.46$, kurtosis $=-0.33$ ). An important change in continuous outcome measures can be estimated as $1 / 2$ a SD of the aggregate score for a given population, ${ }^{28}$ and by this standard a 14-point difference on the SPOC would be considered meaningful. The internal consistency of the SPOC, using all 316 respondents who provided complete data, was 0.94 (Cronbach's alpha).

\section{SCALE VALIDATION}

We used linear least-squares regression with employment status and SF-36 physical component summary (PCS) scores and mental component summary (MCS) scores, acquired 12-months post surgical fixation, as the dependent variables to explore associations between long-term functional outcome, age, gender, smoking status, fracture type (open or closed), multi-trauma vs. isolated tibial fractures, and SPOC scores acquired 6-weeks post surgical fixation. Regression models were restricted to a sample of 196 patients who had complete 12-month follow-up for the SF-36. Demographic and injury-related variables were selected on the basis that they represent covariates commonly thought to affect outcomes in trials of orthopaedic trauma populations. ${ }^{25}$

The SF-36 is a widely accepted, well-validated functional status measure that was developed from the Medical Outcomes Study. ${ }^{29-31}$ It is a self-administered, 36-item questionnaire that measures health-related quality of life in eight domains. Each domain is scored separately from 0 (lowest level) to 100 (highest level). Both PCS and MCS scores can be obtained by summarizing the domains. The SF-36 has demonstrated good construct validity, high internal consistency, and high test-retest reliability and is responsive to improvement in functional recovery in subjects with ankle fractures over the period of one year. ${ }^{32}$ The smallest important difference in the SF-36 is not well-established, and investigators have provided different estimates; however, a 3 to 5 point change in score on a 0 to 100 scale is often cited as a clinically meaningful threshold in evaluating patient changes, based on the work by Stewart and colleagues. ${ }^{33}$ 
Each of the independent variables was initially tested in a simple bivariable regression model. The F-test was used to calculate the level of significance. All variables were entered into a multivariable regression model. A variable was considered statistically significant if it had a p-value $<0.05$ in the final multivariable model. Multicollinearity was deemed concerning if the variance inflation factor for any independent variable was greater than $5 .{ }^{34}$

Patients were asked to rate their pre-injury health status, by SF-36, at the time of enrolment and we have previously shown this to be a valid approach. ${ }^{35,36}$ We explored the effect of including pre-injury SF-36 PCS scores and MCS scores in our adjusted multi-variable regression models to determine if SPOC scores were capturing pre-injury characteristics. For example, it may be that individuals who score high for somatic pre-occupation or poor coping after an injury would have scored equally poorly before their injury. We also explored the effect of including SF-36 PCS scores and MCS scores acquired at 2-weeks post surgical fixation in our multi-variable models, in order to explore if SPOC scores were simply a surrogate for SF-36 PCS scores acquired at an early stage in the recovery process. We did not administer the SPOC questionnaire and the SF-36 at the same time point due to concerns over respondent burden.

\section{Regression Analyses}

Short Form-36-The variance inflation factors of all independent variables were less than 1.1, suggesting that multicollinearity was not a concern and this was the case for all of our linear regression models. Graphical examination of standardized residuals against total SPOC scores did not suggest a violation of the linearity assumption and this was the case for all of our regression models. Patient's age, smoking status, fracture type, and 6-week post surgery SPOC scores were significant predictors of 12-month SF-36 PCS scores in our adjusted model (Table 3).

The unstandardized regression coefficients presented in Table 3 represent the expected differences in SF-36 PCS scores between the subgroup and the reference category. For example, in our adjusted analysis patients who were smokers at the time of their surgery demonstrated an average decrease, versus non-smokers, of 4.28 points $(95 \% \mathrm{CI}=-7.09$ to -1.48 ) on their SF-36 PCS summary scores at 12-months post surgical fixation. For every 14-points on patient's SPOC scores at 6-weeks following surgery they demonstrated an average loss of 2.67 point on their SF-36 PCS scores at 12-months post surgical fixation (unstandardized regression coefficient $=-2.67 ; 95 \% \mathrm{CI}=-3.31$ to -2.03 ). Our adjusted model explained approximately $39 \%$ of the variation (adjusted $\mathrm{R}^{2}=0.39$ ) in SF-36 PCS scores at 12-months post surgical fixation. A large proportion of this explained variation was associated with SPOC scores at 6-weeks after surgery: adding this variable to our model increased the explained variation from $21 \%$ to $39 \%$.

Adding pre-injury SF-36 PCS scores to our multivariable model maintained the explained variation at 39\%, but removing 6-week post surgery SPOC scores reduced the explained variation to $21 \%$. Adding 2-week post surgery SF-36 PCS scores to our multivariable model decreased the explained variation to $37 \%$, and removing 6-week post surgery SPOC scores further reduced it to $19 \%$. Patient's age, smoking status, fracture type, and SPOC scores were significant predictors of 12-month SF-36 PCS scores in both adjusted models, whereas pre-injury SF-36 PCS scores and SF-36 PCS scores acquired 2-weeks post surgical fixation were not ( $\mathrm{p}=0.12$ and $\mathrm{p}=0.10$ respectively).

To assess the ability of the SPOC questionnaire to predict long-term mental functioning, we examined the association between total score and functional outcome, as measured by SF-36 MCS scores, among a sample of 196 patients (Table 4). Only 6-week post surgery SPOC scores were significant predictors of 12-month SF-36 MCS scores in our adjusted model 
(Table 3). Our model explained approximately $30 \%$ of the variation (adjusted $\mathrm{R}^{2}=0.30$ ) in SF-36 MCS scores at 12-months post surgical fixation. The majority of this variation was associated with SPOC scores at 6-weeks after surgery, and adding this variable to our model increased the explained variation from $6 \%$ to $30 \%$.

Adding pre-injury SF-36 MCS scores to our multivariable model increased the explained variation to 35\%, and removing 6-week post surgery SPOC scores reduced the explained variation to $17 \%$. Adding 2-week post surgery SF-36 MCS scores to our multivariable model also increased the explained variation to $35 \%$, and removing 6-week post surgery SPOC scores reduced the explained variation to $26 \%$. SPOC scores were significant predictors of 12-month SF-36 MCS scores in both adjusted models $(\mathrm{p}<0.01)$ as were preinjury SF-36 MCS scores and SF-36 MCS scores acquired 2-weeks post surgical fixation $(\mathrm{p}=<0.01$ and $\mathrm{p}=0.03$ respectively).

Return to Work-Of the 316 patients with complete SPOC data, 263 reported being employed at the time of their injury and $186(71 \%)$ provided their employment status at 12months post-surgery. Sixty-four percent of respondents who were employed at the time of their injury had returned to work at 12 months, and SPOC scores at 6-week post-surgery were highly significant between the 121 who returned to work (mean score $=47.5$ ) and the 72 who did not $($ mean score $=74.7)$; the mean difference in scores was $27.2(95 \% \mathrm{CI}=19.5$ to $34.9 ; \mathrm{p}<0.0001)$.

To assess the ability of the SPOC questionnaire to predict return to work at 1-year, we examined the association between total score and employment status among a sample of 186 patients (Table 5). Patient's age, fracture type, presence of multi-trauma, and 6-week post surgery SPOC scores were significant predictors of return to work at 12-months in our adjusted model. Our adjusted analysis found that for each 14 point increment (14 chosen on the basis of $1 / 2$ a SD) in SPOC score at 6-weeks the odds of returning to work at 12-months decreased by $40 \%$ (odds ratio $=0.60 ; 95 \% \mathrm{CI}=0.50$ to 0.73 ). The pre-test probability of resuming work at 1 -year post-surgery for all patients was 0.64 . Using the likelihood ratios in Table 6 the post-test probability for the $1^{\text {st }}$ quartile (SPOC score of $<35$ ) is 0.89 . The posttest probability for the $4^{\text {th }}$ quartile (SPOC score $>76$ ) is 0.34 .

\section{DISCUSSION}

The SPOC questionnaire is a 27 -item instrument capturing illness beliefs that has been rigorously constructed and validated in a sample of consecutive tibial fracture patients. The SPOC score is highly predictive of functional outcomes 1 year after surgical fixation. SPOC scores at 6-weeks post-surgery accounted for $18 \%$ of the variation in patient-reported physical function and mental function, as measured by SF-36 PCS and MCS scores respectively, were strongly predictive of employment status at 1-year, and were a far more powerful predictor of functional recovery than age, gender, fracture type, smoking status, or the presence of multi-trauma.

\section{Strengths and Limitations}

The strengths of our study include a large sample of consecutive patients presenting with similar injuries that were all assessed at the same time point with the SPOC questionnaire and followed prospectively. Our patients were part of a randomized controlled trial in which the surgical procedure (reamed or unreamed intramedullary nailing) and post-operative care was standardized, which limits the impact that these variables may have had on clinical outcome. 
Our study does have some limitations. After a patient's fracture was declared healed by their attending surgeon they were no longer required to attend the fracture clinic, which lowered follow-up rates for making observations on quality of life. Hence, our follow-up rates for completed SF-36 questionnaires dropped from $83 \%$ at discharge to $53 \%$ at 12 month postsurgery, which affected the sample available for our validation analyses $(62 \% ; 196$ of 316). Analysis of demographic variables, injury characteristics, and average SPOC scores found no statistically significant differences between the full trial population and the subgroups used in our analyses (Table 1).

We used a simple summary score for the SPOC questionnaire. It could be argued that some items are more important than others and should therefore make a larger contribution to the final score. Weighting items leads to greater complexity in calculating a final score, and numerous studies have found that as long as items with very low loading are eliminated, weighting is unnecessary. ${ }^{37,38}$ Our instrument satisfied this criteria as all of the items comprising the SPOC questionnaire demonstrated factor loading from 0.43 to 0.74 (Table 2). Despite our attempts to build comprehensive regression models we only explained $39 \%$ of the variation in SF-36 PSC scores and 30\% of the variation in SF-36 MCS at 12-months post surgery. Future efforts should explore additional potentially predictive variables, such as co-morbidity, ${ }^{39,40}$ compensation status and ongoing litigation ${ }^{41,42}$. The sample we used for validating the SPOC was a subsample of the patients whose data was used to develop our questionnaire, and the association between SPOC questionnaire scores and functional outcomes may be inflated because of non-independence. Therefore, our results should be confirmed in an independent sample of tibial fracture patients. Furthermore, the generalizability of our results to other populations is uncertain and will require investigation.

\section{Relevance of Our Findings}

Costs related to trauma care in the United States alone have been estimated to exceed 400 billion dollars annually. ${ }^{43}$ In an effort to reduce costs and improve outcomes investigators have conducted several studies to identify modifiable predictors of recovery; however, such efforts have largely focused on demographic and injury-related characteristics. ${ }^{44-47}$ Despite mounting evidence that non-injury related factors have an important role in recovery from trauma, specific variables associated with clinical outcomes are poorly understood. ${ }^{48-50}$ Further, there are no validated instruments available to capture the impact of illness beliefs that are predictive of functional recovery following trauma. This lack of knowledge complicates efforts to improve the care of orthopaedic trauma patients.

Lazarus argues that all individuals appraise events in order to establish the associated level of threat, and that this process triggers the selection of coping strategies ${ }^{51}$ Individuals with a strong sense of self-efficacy view challenging problems as tasks to be mastered and recover quickly from setbacks. Individuals with a weak sense of self-efficacy avoid challenging tasks, tend to believe that difficult situations are beyond their capabilities, and focus on negative outcomes. ${ }^{52,53}$ Coping beliefs begin to form during childhood; however, they continue to evolve throughout life as one acquires new skills, experiences, and understanding. 54

There are a number of systematic reviews that have shown patients' perceptions regarding their illness experience can be modified, and that such efforts can improve outcomes. ${ }^{55-57}$. Moss-Morris and colleagues explored the effect of cognitive behavioural therapy among patients attending a multidisciplinary chronic pain clinic and found that changes in cognitive processes accounted for $26 \%$ of the variation in improved SF-36 PCS scores. ${ }^{58}$ The SPOC questionnaire is the first validated instrument that captures illness beliefs among orthopaedic trauma patients, and is highly predictive of functional outcome at 1-year. This suggests the 
possibility that trauma patients with unhelpful illness beliefs could be identified early in the treatment process and targeted for concurrent therapy designed to modify such cognitions.

It remains to be established if the illness beliefs captured by the SPOC questionnaire are amenable to modification, or if such modifications would lead to important improvement to functional outcome. The range of scores on the SPOC questionnaire that would be most helpful in identifying trauma patients who are most likely to benefit from treatment directed at modifying unhelpful illness beliefs also remains uncertain.

\section{Acknowledgments}

We thank Dr Steven Reid, Clinical Research Fellow, Academic Department of Psychological Medicine, Guy's, King's and St. Thomas' School of Medicine and Institute of Psychiatry, for helpful consultation in regards to existing, relevant, questionnaires.

The Medically Unexplained Syndromes Study Group is comprised of the following individuals: Dr. Maziar Badii, Dr. Arthur Barsky, Dr. Jason W. Busse, Dr. John Dufton, Dr. Nelson Greidanus, Dr. Gordon H. Guyatt, Dr. Catherine Krasnik, Dr. Victor M. Montori, Dr. Edward Mills, Dr. Roohi Qureshi, Dr. Steven Reid, and Dr. Ping $\mathrm{Wu}$.

Funding: This Study was funded by Research Grants from the Canadian Institutes of Health Research \# MCT-38140 [PI: G. Guyatt], National Institutes of Health NIAMS-072; R01 AR48529 [PI: M. Swiontkowski], Orthopaedic Research and Education Foundation [American Academy of Orthopaedic Surgeons [PI: P. Tornetta III], Orthopaedic Trauma Association [PI: M. Bhandari]. Smaller site specific grants were also obtained from Hamilton Health Sciences Research Grant [PI: M. Bhandari] and Zimmer [PI: M. Bhandari]. No funds were received for the preparation of this manuscript. Dr. Busse is funded by a New Investigator Award from the Canadian Institutes of Health Research and Canadian Chiropractic Research Foundation. Dr. Bhandari is supported, in part, by a Canada Research Chair, McMaster University.

Role of Funding Agencies: The funding sources had no role in design or conduct of the study; the collection, management, analysis, or interpretation of the data; or the preparation, review, or approval of the manuscript.

\section{REFERENCES}

1. Goldberg WM. Belief and health. Annals RCPSC. 1999; 32:139-141.

2. Weinman J, Petrie KJ. Illness perceptions: a new paradigm for psychosomatics? J Psychosom Res. 1997; 42:113-116. [PubMed: 9076639]

3. Mondloch MV, Cole DC, Frank JW. Does how you do depend on how you think you'll do? A systematic review of the evidence for a relation between patient's recovery expectations and health outcomes. CMAJ. 2001; 165:174-179. [PubMed: 11501456]

4. Cole DC, Mondloch MV, Hogg-Johnson S. Listening to injured workers: How recovery expectations predict outcomes - a prospective study. CMAJ. 2002; 166:749-754. [PubMed: 11944761]

5. Myers SS, Phillips RS, Davis RB, et al. Patient expectations as predictors of outcome in patients with acute low back pain. J Gen Intern Med. 2008; 23:148-153. [PubMed: 18066631]

6. Holm LW, Carroll LJ, Cassidy JD, et al. Expectations for recovery important in the prognosis of whiplash injuries. PLoS Med. 2008; 5:e105. [PubMed: 18479182]

7. Linton SJ, Halldén K. Can we screen for problematic back pain? A screening questionnaire for predicting outcome in acute and subacute back pain. Clin J Pain. 1998; 14:209-215. [PubMed: 9758070]

8. McBeth J, Macfarlane GJ, Benjamin S, et al. Features of somatization predict the onset of chronic widespread pain. Arthritis Rheum. 2001; 44:940-946. [PubMed: 11315933]

9. Beaton DE, Tarasuk V, Katz JN, et al. "Are you better ?" a qualitative study of the meaning of recovery. Arthritis Care Res. 2001; 45:270-279.

10. Einhorn TA. Enhancement of fracture healing. J Bone Joint Surg [Am]. 1995; 77A:940-956.

11. Heckman JD, Sarasohn-Kahn J. The economics of treating fracture healing. Bull Hosp Jt Dis. 1997; 56:63-72. [PubMed: 9063607] 
12. Kirshner B, Guyatt GH. A Methodological Framework for Assessing Health Indices. J Chron Dis. 1985; 38:27-36. [PubMed: 3972947]

13. Tidermark J, Zethraeus N, Svensson O, et al. Quality of life related to fracture displacement among elderly patients with femoral neck fractures treated with internal fixation. J Orthop Trauma. 2002; 16:34-38. [PubMed: 11782631]

14. Obremskey WT, Dirschl DR, Crowther JD, et al. Change over time of SF-36 functional outcomes for operatively treated unstable ankle fractures. J Orthop Trauma. 2002; 16:30-33. [PubMed: 11782630]

15. Hee HT, Wong HP, Low YP, et al. Predictors of outcome of floating knee injuries in adults: 89 patients followed for 2-12 years. Acta Orthop Scand. 2001; 72:385-394. [PubMed: 11580128]

16. Sarmiento A, Sharpe FE, Ebramzadeh E, et al. Factors influencing the outcome of closed tibial fractures treated with functional bracing. Clin Orthop Rel Res. 1995; 315:8-24.

17. Vanderschot P, Vanderspeeten K, Verheyen L, et al. A review on 161 subtrochanteric fractures-risk factors influencing outcome: age, fracture pattern and fracture level. Unfallchirurg. 1995; 98:265-271. [PubMed: 7610387]

18. Nilsson LT, Johansson A, Stromqvist B. Factors predicting healing complications in femoral neck fractures. 138 patients followed for 2 years. Acta Orthop Scand. 1993; 64:175-177. [PubMed: 8498180]

19. Alho A, Benterud JG, Ronningen H, et al. Prediction of disturbed healing in femoral neck fracture. Radiographic analysis of 149 cases. Acta Orthop Scand. 1992; 63:639-644. [PubMed: 1471513]

20. Goldberg, DP.; Williams, P. The user's guide to the general health questionnaire. NFER-Nelson; Windsor: 1998.

21. Derogatis LR, Lipman RS, Covi L. SCL-90: an outpatient psychiatric rating scale--preliminary report. Psychopharmacol Bull. 1973; 9:13-28. [PubMed: 4682398]

22. Chalder T, Berelowitz C, Pawlikowska T. Development of a fatigue scale. J Psychosomatic Res. 1993; 37:147-154.

23. Speckens AE, Spinhoven P, Sloekers PP, et al. A validation study of the Whitely Index, the Illness Attitude Scales, and the Somatosensory Amplification Scale in general medical and general practice patients. J Psychosom Res. 1996; 40:95-104. [PubMed: 8730649]

24. Study to Prospectively Evaluate Reamed Intramedullary Nails in Patients with Tibial Fractures Investigators. Bhandari M, Guyatt G, Tornetta P 3rd, et al. Randomized trial of reamed and unreamed intramedullary nailing of tibial shaft fractures. J Bone Joint Surg [Am]. 2008; 90:25672578.

25. SPRINT Investigators. Bhandari M, Guyatt G, Tornetta P 3rd, et al. Study to prospectively evaluate reamed intramedually nails in patients with tibial fractures (S.P.R.I.N.T.): study rationale and design. BMC Musculoskelet Disord. 2008; 9:91. [PubMed: 18573205]

26. Norman, G.; Streiner, D. Principal Components and Factor Analysis. In: Norman, G.; Streiner, D., editors. Biostatistics. The bare essentials. 2nd ed. B.C. Decker Inc.; Hamilton, ON: 2000. p. 163-77.

27. Hutcheson, GD.; Sofroniou, N. The Multiple Social Scientist: Introductory Statistics using Generalized Linear models. Sage Publications; London: 1999.

28. Norman GR, Sloan JA, Wyrwich KW. Interpretation of changes in health-related quality of life: the remarkable universality of half a standard deviation. Med Care. 2003; 41:582-592. [PubMed: 12719681]

29. Ware JE, Sherbourne CD. The MOS 36-Item short form health survey (SF-36). Conceptual framework and item selection. Med Care. 1992; 30:473-483. [PubMed: 1593914]

30. McHorney CA, Ware JE, Lu JF, et al. The mos 36-item short form health survey (SF-36): Tests of data quality, scaling assumptions, and reliability across diverse patient groups. Med Care. 1994; 32:40-66. [PubMed: 8277801]

31. Greenwood DC, Muir KR, Doherty M, et al. Conservatively managed tibial shaft fractures in Nottingham UK: are pain, osteoarthritis, and disability long-term complications? J Epidemiol Community Health. 1997; 51:701-704. Greenwood DC , Muir KR, Doherty M et al. [PubMed: 9519136] 
32. Bhandari M, Sprague S, Busse JW, et al. Health-Related Quality of Life following Operative Treatment of Unstable Ankle Fractures: A Prospective Observational Study. J Orthop Trauma. 2004; 18:338-345. [PubMed: 15213498]

33. Stewart AL, Greenfield S, Hays RD, et al. Functional status and well-being of patients with chronic conditions. Results from the Medical Outcomes Study. JAMA. 1989; 262:907-913. [PubMed: 2754790]

34. Belsley, DA.; Kuh, E.; Welsch, RE. Regression Diagnostics: Identifying Influential Data and Sources of Collinearity. John Wiley \& Sons; New York: 1980.

35. Bryant D, Norman G, Stratford P, et al. Patients undergoing knee surgery provided accurate ratings of preoperative quality of life and function 2 weeks after surgery. J Clin Epidemiol. 2006; 59:984993. [PubMed: 16895823]

36. Bryant D, Stratford P, Marx R, et al. Patients can provide a valid assessment of quality of life, functional status, and general health on the day they undergo knee surgery. J Bone Joint Surg [Am]. 2008; 90:264-270.

37. Wainer H. Estimating coefficients in linear models: It don't make no nevermind. Psychol Bull. $1976 ; 83: 213-217$.

38. Streiner, DL.; Norman, GR. Health Measurement Scales. A Practical Guide to their Development and Use. 2nd ed. Oxford University Press; Oxford: 1995. From Items to Scales.

39. Starr AJ. Fracture repair: successful advances, persistent problems, and the psychological burden of trauma. J Bone Joint Surg [Am]. 2008; 90(Suppl 1):132-137.

40. McCarthy ML, MacKenzie EJ, Edwin D, et al. LEAP study group. Psychological distress associated with severe lower-limb injury. J Bone Joint Surg [Am]. 2003; 85:1689-1697.

41. Harris I, Mulford J, Solomon M, et al. Association between compensation status and outcome after surgery: a meta-analysis. JAMA. 2005; 293:1644-1652. [PubMed: 15811984]

42. Bhandari M, Busse JW, Hanson BP, et al. Psychological distress and quality of life after orthopedic trauma: an observational study. Can J Surg. 2008; 51:15-22. [PubMed: 18248701]

43. Committee on Injury Prevention and Control, Institute of Medicine. Reducing the Burden of Injury: Advancing Prevention and Treatment. National Academy Press; Washington: 1999.

44. Moed B, Yu P, Gruson K. Functional Outcomes of Acetabular Fractures. J Bone Joint Surg [Am]. 2003; 85:1879-1883.

45. Pollak A, McCarthy M, Bess S, et al. Outcomes After Treatment of High-Energy Tibial Plafond Fractures. J Bone Joint Surg [Am]. 2003; 85:1893-1900.

46. Adams J, Davis G, Alexander CB, et al. Pelvic Trauma in Rapidly Fatal Motor Vehicle Accidents. J Orthop Trauma. 2003; 17:406-410. [PubMed: 12843724]

47. Richmond J, Aharonoff GB, Zuckerman JD, et al. Mortality Risk After Hip Fracture. J Orthop Trauma. 2003; 17(Suppl):S2-S5. [PubMed: 14696770]

48. Suter PB. Employment and litigation: improved by work, assisted by verdict. Pain. 2002; 100:249257. [PubMed: 12467996]

49. MacDermid JC, Donner A, Richards RS, et al. Patient versus injury factors as predictors of pain and disability six months after a distal radius fracture. J Clin Epidemiol. 2002; 55:849-854. [PubMed: 12393071]

50. Mock C, MacKenzie E, Jurkovich G, et al. Determinants of disability after lower extremity fracture. J Trauma. 2000; 49:1002-1011. [PubMed: 11130480]

51. Lazarus, RS. Psychological Stress and the Coping Process. McGraw-Hill; New York: 1966.

52. Bandura A. Self-efficacy: Toward a unifying theory of behavioral change. Psychological Review. 1977; 84:191-215. [PubMed: 847061]

53. Bandura, A. Exercise of personal agency through the self-efficacy mechanisms. In: Schwarzer, R., editor. Self-efficacy: Thought control of action. Hemisphere; Washington, DC: 1992.

54. Bandura, A. Self-efficacy. In: Ramachaudran, VS., editor. Encyclopedia of human behavior. 4th ed. Academic Press; New York: 1994.

55. Chou R, Huffman LH, American Pain Society; American College of Physicians. Nonpharmacologic therapies for acute and chronic low back pain: a review of the evidence for an 
American Pain Society/American College of Physicians clinical practice guideline. Ann Intern Med. 2007; 147:492-504. [PubMed: 17909210]

56. Astin JA, Beckner W, Soeken K, et al. Psychological interventions for rheumatoid arthritis: a metaanalysis of randomized controlled trials. Arthritis Rheum. 2002; 47:291-302. [PubMed: 12115160]

57. Morley S, Eccleston C, Williams A. Systematic review and meta-analysis of randomized controlled trials of cognitive behaviour therapy and behaviour therapy for chronic pain in adults, excluding headache. Pain. 1999; 80:1-13. [PubMed: 10204712]

58. Moss-Morris R, Humphrey K, Johnson MH, et al. Patients' perceptions of their pain condition across a multidisciplinary pain management program: do they change and if so does it matter? Clin J Pain. 2007; 23:558-564. [PubMed: 17710004] 
Table 1

Demographic characteristics of patients.

\begin{tabular}{|c|c|c|c|}
\hline & Total Sample & $\begin{array}{l}\text { Sample with } \\
\text { Complete SPOC } \\
\text { Data }\end{array}$ & $\begin{array}{l}\text { Sample with } \\
\text { Complete SPOC } \\
\text { \& SF-36 Data at } \\
12 \text { months }\end{array}$ \\
\hline $\mathrm{N}$ & 1319 & 316 & 196 \\
\hline $\begin{array}{l}\text { Age at discharge, mean } \\
\text { (SD) }\end{array}$ & $39.2(15.9)$ & $38.1(16.0)$ & $38.4(15.6)$ \\
\hline \multicolumn{4}{|l|}{ Gender, n (\%) } \\
\hline Male & $979(74.2 \%)$ & $236(74.7 \%)$ & $148(75.5 \%)$ \\
\hline Female & $340(25.8 \%)$ & $80(25.3 \%)$ & $48(24.5 \%)$ \\
\hline Current Smoker, n (\%) & $446(34.0 \%)$ & $112(35.4 \%)$ & $59(30.1 \%)$ \\
\hline Open Fractures, n (\%) & $435(32.8 \%)$ & $120(38.0 \%)$ & $71(36.2 \%)$ \\
\hline Closed Fractures, n (\%) & $892(67.2 \%)$ & $196(62.0 \%)$ & $125(63.8 \%)$ \\
\hline \multicolumn{4}{|l|}{$\begin{array}{l}\text { Gustilo Grade for Open } \\
\text { Fractures }\end{array}$} \\
\hline I & $119(27.0 \%)$ & $32(26.7 \%)$ & $18(25.4 \%)$ \\
\hline II & $171(38.9 \%)$ & $42(35.0 \%)$ & $22(31.0 \%)$ \\
\hline IIIA & $118(26.8 \%)$ & $36(30.0 \%)$ & $21(29.6 \%)$ \\
\hline IIIB & $33(7.5 \%)$ & $10(8.3 \%)$ & $10(14.1 \%)$ \\
\hline \multicolumn{4}{|l|}{$\begin{array}{l}\text { Tscherne Grade for Closed } \\
\text { Fractures }\end{array}$} \\
\hline 0 & $273(30.4 \%)$ & $49(24.4 \%)$ & $31(24.2 \%)$ \\
\hline 1 & $460(51.2 \%)$ & $105(52.2 \%)$ & $70(54.7 \%)$ \\
\hline 2 & $144(16.0 \%)$ & $41(20.4 \%)$ & $25(19.5 \%)$ \\
\hline 3 & $21(2.3 \%)$ & $6(3.0 \%)$ & $2(1.6 \%)$ \\
\hline Isolated Fractures, n (\%) & $888(67.3 \%)$ & $190(60.1 \%)$ & $116(59.2 \%)$ \\
\hline Multi-trauma, n (\%) & $431(32.7 \%)$ & $126(39.9 \%)$ & $80(40.8 \%)$ \\
\hline \multicolumn{4}{|l|}{ SF-36 PCS } \\
\hline pre-injury, mean (SD) & $52.9(9.1)$ & $53.8(8.1)$ & $54.5(6.7)$ \\
\hline 2-weeks, ${ }^{* *}$ mean $(\mathrm{SD})$ & $28.2(7.6)$ & $27.2(7.1)$ & $27.3(6.8)$ \\
\hline 12 -months, ${ }^{* *}$ mean $(\mathrm{SD})$ & $43.2(11.3)$ & $43.2(11.2)$ & $43.2(11.2)$ \\
\hline \multicolumn{4}{|l|}{ SF-36 MCS } \\
\hline pre-injury, mean (SD) & $54.0(8.6)$ & $54.3(8.5)$ & $54.4(8.1)$ \\
\hline 2-weeks, ${ }^{* *}$ mean $(\mathrm{SD})$ & $45.5(12.6)$ & $44.7(12.9)$ & $44.8(12.7)$ \\
\hline 12 -months, ${ }^{* *}$ mean $(\mathrm{SD})$ & $51.7(11.9)$ & $51.3(12.3)$ & $51.3(12.1)$ \\
\hline Mean SPOC Score (SD) & & $57.1(28.5)$ & $54.9(28.4)$ \\
\hline
\end{tabular}

J Orthop Trauma. Author manuscript; available in PMC 2013 June 01. 
* Some multi-trauma patients presented with bilateral tibial fractures, resulting in the total number of open and closed fractures being greater than the total number of patients.

*** Post-injury.

Differences between groups were non-significant $(\mathrm{p}>0.05)$ for all variables. 
Table 2

Factor Loadings of SPOC Items on 4 Factors

\begin{tabular}{|c|c|c|c|c|}
\hline & \multicolumn{4}{|c|}{ Component } \\
\hline Questionnaire Item & 1 & 2 & 3 & 4 \\
\hline \multicolumn{5}{|l|}{ Somatic complaints } \\
\hline Muscles hurt after exercise & .744 & & & \\
\hline Muscles hurt at rest & .719 & & & \\
\hline Experienced pain in the last week & .707 & & & \\
\hline Experienced stiff joints in the past week & .674 & & & \\
\hline Experienced heavy feelings in arms or legs in the past week & .580 & & & \\
\hline Experienced problems with sleep in the past week & .558 & & & \\
\hline Experienced loss of strength in the past week & .532 & & .404 & \\
\hline Experienced balance problems in the past week & .513 & & & \\
\hline Felt lower back pain in the past week & .476 & & & \\
\hline Feeling weak in the past week & .458 & & .455 & \\
\hline \multicolumn{5}{|l|}{$\underline{\text { Coping }}$} \\
\hline Lost sleep over worry in the past week & & .713 & & \\
\hline Thinking of yourself as a worthless person in the past week & & .680 & & \\
\hline Felt you couldn't overcome your difficulties in the past week & & .613 & & \\
\hline Experienced hot or cold spells in the past week & & .585 & & \\
\hline Felt under constant strain in the past week & & .585 & & \\
\hline Feeling reasonably happy in the past week & & .553 & & \\
\hline \multicolumn{5}{|l|}{ Energy } \\
\hline Difficulty concentrating & & & .668 & \\
\hline Poor memory & & & .631 & \\
\hline Feeling low in energy or slowed down in the past week & & & .551 & \\
\hline Problems starting things & .410 & & .506 & \\
\hline Less strength in your muscles & & & .496 & \\
\hline Need to rest more & & & .465 & \\
\hline Experienced fatigue in the past week & & & .427 & \\
\hline \multicolumn{5}{|l|}{ Optimism } \\
\hline My treatment will be effective in curing my injury & & & & .732 \\
\hline The symptoms due to my injury will improve with time & & & & .675 \\
\hline There is a lot that I can do to control my injury-related symptoms & & & & .632 \\
\hline The symptoms due to my injury will last a short time & & & & .619 \\
\hline
\end{tabular}




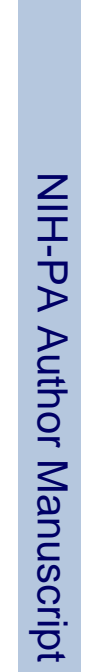

ᄒํ.

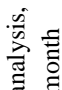

學

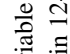

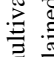

$\frac{\sqrt{2}}{\sqrt[3]{5}}$

$\Xi$

을

突

它

倇 


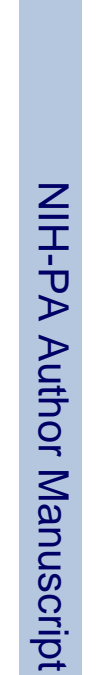

ธิ

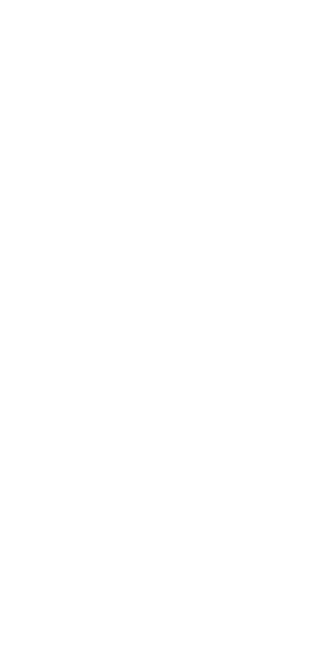

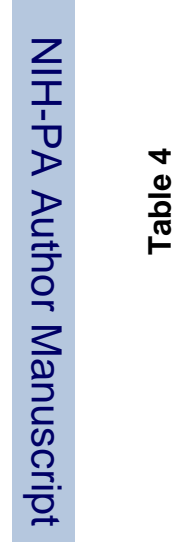
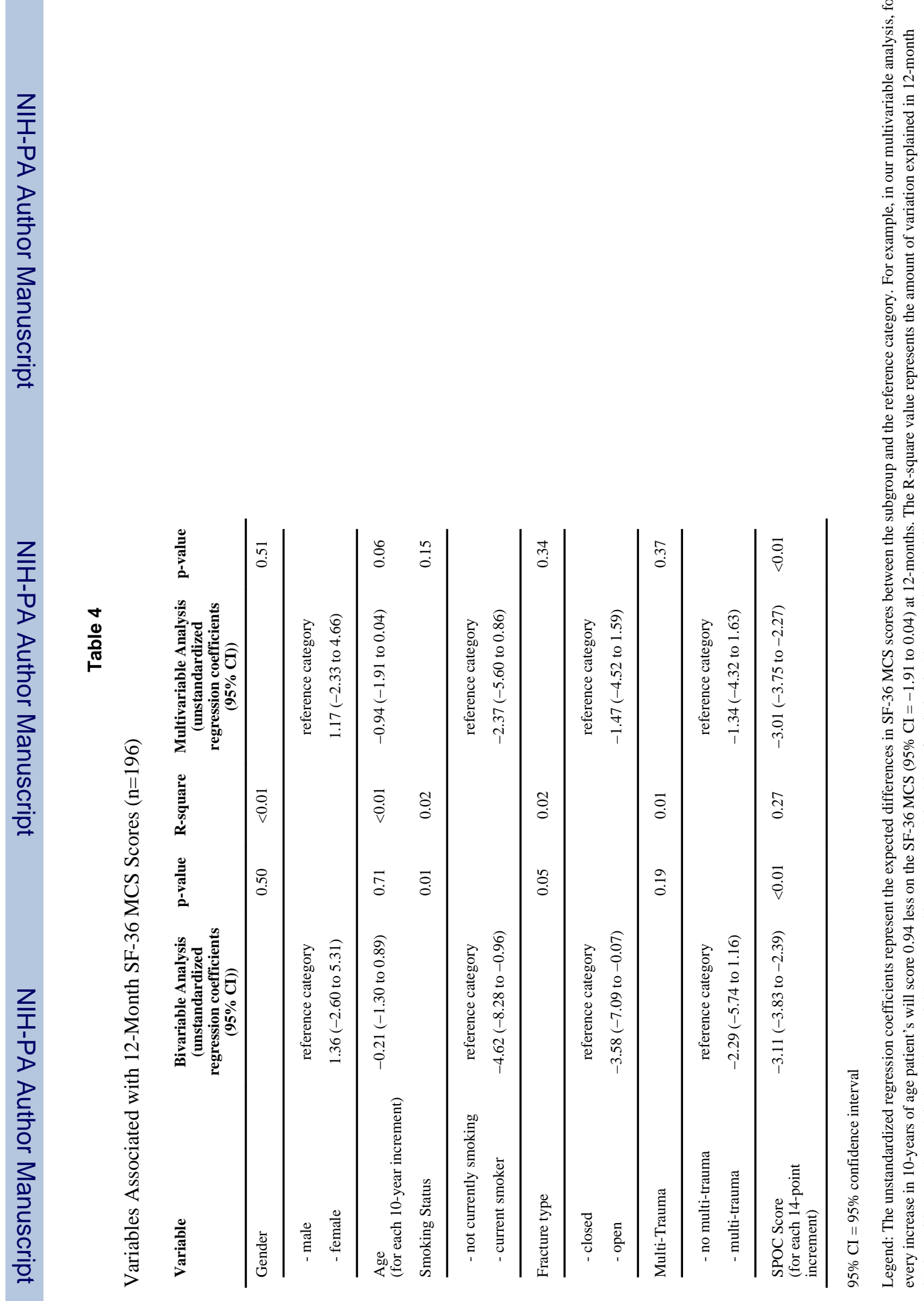

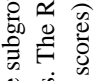

$\begin{array}{ll} & \\ 0 & 0 \\ 0 & 0 \\ 0 & 0 \\ 0 & 0 \\ 0\end{array}$

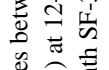

苟 它

y

通需

步

ชै



氖施离

要

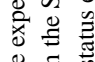

要

总吉

논

焉

策

氖

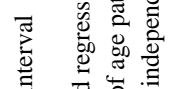

芯

总 密

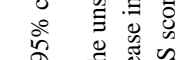

至

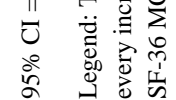

J Orthop Trauma. Author manuscript; available in PMC 2013 June 01. 
Table 5

Variables Associated with Return to Work at 12-Months $(\mathrm{n}=186)$

\begin{tabular}{|c|c|c|c|c|}
\hline Variable & $\begin{array}{c}\text { Bivariable Analysis } \\
\text { odds ratio } \\
(95 \% \mathrm{CI})\end{array}$ & p-value & $\begin{array}{c}\text { Multivariable Analysis * } \\
\text { odds ratio } \\
(95 \% \mathrm{CI})\end{array}$ & p-value \\
\hline Gender & & 0.69 & & 0.48 \\
\hline - male & reference category & & reference category & \\
\hline - female & $0.87(0.43$ to 1.73$)$ & & $0.74(0.33$ to 1.69$)$ & \\
\hline $\begin{array}{l}\text { Age } \\
\text { (for each 10-year increment) }\end{array}$ & $0.86(0.71$ to 1.05$)$ & 0.14 & $0.74(0.58$ to 0.94$)$ & 0.01 \\
\hline Smoking Status & & 0.05 & & 0.32 \\
\hline - not currently smoking & reference category & & reference category & \\
\hline - current smoker & $0.54(0.29$ to 1.01$)$ & & $0.68(0.32$ to 1.45$)$ & \\
\hline Fracture type & & $<0.01$ & & 0.01 \\
\hline - closed & reference category & & reference category & \\
\hline - open & $0.37(0.20$ to 0.68$)$ & & $0.36(0.18$ to 0.74$)$ & \\
\hline Multi-Trauma & & 0.01 & & 0.02 \\
\hline - no multi-trauma & reference category & & reference category & \\
\hline - multi-trauma & $0.44(0.24$ to 0.79$)$ & & $0.44(0.22$ to 0.89$)$ & \\
\hline $\begin{array}{l}\text { SPOC Score } \\
\text { (for each 14-point } \\
\text { increment) }\end{array}$ & $0.69(0.61$ to 0.78$)$ & $<0.01$ & $0.60(0.50$ to 0.73$)$ & $<0.01$ \\
\hline
\end{tabular}

Key: $95 \% \mathrm{CI}=95 \%$ confidence interval

Analysis is adjusted for age, gender, smoking status, fracture type (open or closed), and multi-trauma 
Table 6

Odds of Return to Work at 12-Months according to 6-week SPOC scores $(n=186)$

\begin{tabular}{|c|c|c|}
\hline SPOC quartile & $\begin{array}{c}\text { Multivariable Analysis } \\
\text { odds ratio } \\
(95 \% \text { CI })\end{array}$ & $\begin{array}{l}\text { Likelihood } \\
\text { Ratio } \\
(95 \% \text { CI })\end{array}$ \\
\hline $\begin{array}{l}1^{\text {st }} \text { quartile } \\
(\text { scores } \leq 35)\end{array}$ & $\begin{array}{c}6.86 \\
\text { (2.48 to } 18.97)\end{array}$ & $\begin{array}{c}4.62 \\
(1.92 \text { to } 11.11)\end{array}$ \\
\hline $\begin{array}{l}2^{\text {nd }} \text { quartile } \\
\text { (35.1 to } 53.5 \text { ) }\end{array}$ & $\begin{array}{c}1.37 \\
(0.65 \text { to } 2.89)\end{array}$ & $\begin{array}{c}1.36 \\
(0.81 \text { to } 2.28)\end{array}$ \\
\hline $\begin{array}{l}3^{\text {rd }} \text { quartile } \\
(53.6 \text { to } 76)\end{array}$ & $\begin{array}{c}1.15 \\
(0.53 \text { to } 2.49)\end{array}$ & $\begin{array}{c}0.79 \\
(0.47 \text { to } 1.34)\end{array}$ \\
\hline $\begin{array}{l}4^{\text {th }} \text { quartile } \\
(\text { scores }>76)\end{array}$ & $\begin{array}{c}0.21 \\
(0.10 \text { to } 0.47)\end{array}$ & $\begin{array}{c}0.29 \\
(0.17 \text { to } 0.51)\end{array}$ \\
\hline
\end{tabular}

* Analysis is adjusted for age, gender, smoking status, fracture type (open or closed), and multi-trauma 